behavioural and brain data, but only if we also assume a literal 'mind's eye' that is very much like a real eye, complete with a pattern of spatial resolution, a visual angle and a way of scanning with mental 'eyemovements'. On the other hand, if we take the nonliteral option, then empirical results otherwise attributed to the geometry of the image and the 'mind's eye' must now be built into the interaction between the image and the access process. Because there are no independent constraints on such a process, we are free to tailor it to fit the data. But we do pay a price because now there is nothing left of the idea of a depictive, geometry-preserving pictorial entity, and so there is no need to involve the visual system.

Kosslyn's book is at its best when it skirts the question of the nature of images and focuses instead on the commonality of vision and visual imagery. Both behavioural and neural evidence is presented that suggests that vision and imagery may use common brain mechanisms. Although the evidence is far from unambiguous (especially evidence from the superposition of images and percepts, for which there is a simple attention-based 'indexing' explanation) it is nonetheless intriguing and worth examining in detail. On the other hand, this approach belies the goal of the book: it is irrelevant to the debate about the nature of images.

Nobody doubts that some brain mechanisms are involved in both vision and imaging. The interesting question is which mechanisms they share, because the answer might illuminate what, if anything, is special about visualizing as opposed to general reasoning. If it could be shown that imagery uses mechanisms that are specific to vision, then we would have discovered something of considerable interest - even though it would still not address the traditional 'imagery debate'. Mechanisms specific to vision might, for example, include those responsible for the segregation of figure from ground, spontaneous construction of three-dimensional percepts from two-dimensional contours or motion cues, or any of the many distinctly visual phenomena described in textbooks on visual perception. Kosslyn's book provides no unproblematic evidence implicating this kind of mechanism. What it provides instead is some speculation about why positing internal pictures helps to explain perceptual invariances and the integration of information from glances - speculation that helps only to perpetuate the misleading subjective experience we have that when we see or imagine something we are creating a replica of it in our heads, an idea that has surely run its course over the past two millennia.

Zenon Pylyshyn is in the Center for Cognitive Science, Rutgers University, New Brunswick, New Jersey 08903, USA.
Minds possessed

\section{Susan Blackmore}

Dark White: Aliens, Abductions and the UFO Obsessions. By Jim Schnabel. Hamish Hamilton: 1994. Pp. 304. £16.99.

How can apparently sane, intelligent and likeable people believe that four-foot-high aliens are visiting our planet and abducting people? If you are perplexed by this question, Jim Schnabel's latest book Dark White (Grey - geddit?) will give you some answers.

A recent Roper opinion poll claimed that nearly four million Americans have been abducted. The stories are remarkably consistent as well as outrageous. People are woken in the dead of night or, less commonly, taken from their car or workplace, and confronted by large-headed, small-bodied, huge-eyed grey aliens who transport them magically into a spacecraft. Here they are taken down curved corridors, laid on a flat table and subjected to humiliating or terrifying mental, medical and gynaecological procedures. Eventually they find themselves back in bed but with two or three hours 'missing'.

The stories cry out for comparison with fairy abductions, incubi and succubi and myths such as the Old Hag of Newfoundland, who visits victims at night and tries to suffocate them. Schnabel deals well with all of these but his greatest strength lies in the way he portrays the main characters involved.

Take Budd Hopkins, a New York artist who first saw a UFO in 1964 . He began to investigate experiences of 'missing time' and found himself overwhelmed by people needing help. Perhaps it was because he was already well known as an artist that people took him seriously. He learned how to hypnotize them and soon they were 'remembering' the abductions that took place in the missing time intervals.

Schnabel portrays Hopkins as a kindly and sincere man who really wanted to understand what was going on. The vividness and consistency of the stories persuaded him of the nuts-and-bolts reality of the aliens and their UFOs. It was also Hopkins who first came across stories of the alien hybridization programme. As Schnabel points out, as soon as Budd recognized it, women began turning up with strange scars and tales of disappearing pregnancies, and men told of having sperm removed by beautiful female aliens.

Contrasting with the sincerity of a possibly naive artist is the craziness of Whitley Strieber. The way Schnabel describes him you would not trust his opinion of what he had for breakfast, let alone the reality of his aliens. His best-selling book Communion followed several horror nov- els that, according to Schnabel, mix fiction and biography with alarming ease - and apparently it was going to be called Body Terror until Strieber decided that it must not frighten people.

This tension between terror and enlightenment runs through the whole story. Whereas Hopkins' abductees seemed only to experience pain and fear, those studied by Leo Sprinkle, a psychologist from Wyoming, more often reported spiritual experiences and "environmental and spiritual consciousness-raising". Joining this clan was soon to be John Mack, well known as a Pulitzer prizewinning author and professor of psychiatry at Harvard University. With such qualifications he had an authority perhaps greater than any of the others involved. He soon collected a large following of abductees convinced that the aliens had peaceful intent and wanted to warn us of impending environmental disaster.

Like Mack, Ken Ring, a psychologist, sees the positive side. He had studied near-death experiences and noted the similarities between these and abductions. Both pointed to the progress of human consciousness towards unity and harmony.

A problem for anyone who simply wants to know whether or not the aliens exist is that these academics, unlike the more down-to-earth Hopkins, can evade such a crude question: after all, it depends on what one means by reality. But what of the science?

There is certainly a scientific story to be told. Yet, with no index or proper references, this book fails to tell it well enough. This is a shame because the groundwork is all there. Schnabel tackles sleep paralysis, in which the muscle paralysis of dreaming sleep can carry over into waking, and compares it with abduction myths. He considers childhood trauma, the problems of hypnosis and the arguments over false memory.

Best of all he clearly explains the most tricky - and interesting - of the theories. Michael Persinger, a Canadian neuroscientist, argues that the experiences are caused by firing in the temporal lobes of the brain and can be set off by changes in magnetic fields. Schnabel marshals the evidence for this theory and concludes that abduction accounts may all be similar not because the aliens are all similar but because our brains are. Stimulation of the relevant areas, combined with cultural and personal material, may account for it all.

The book convinced me that abduction accounts are well worth serious research. It is not a question of whether or not the aliens exist but of what the experiences have to tell us about our minds and brains.

Susan Blackmore is in the Department of Psychology, University of the West of England, Bristol BS16 2JP, UK. 